\section{Respiratory acidosis and subcutaneous emphysema during laparoscopic cholecystectomy}

Derek J. Pearce MD CCFP (EM)

\begin{abstract}
A case is presented of a healthy 69-yr-old woman who underwent elective laparoscopic cholecystectomy under general anaesthesia. As surgery proceeded she developed hypercapnia (arterial blood $\mathrm{PaCO}_{2}=100 \mathrm{mmHg}$ ) and a related respiratory acidosis (arterial blood pH 707). The cause was attributed to subcutaneous insulflation and absorption of $\mathrm{CO}_{2}$, directly related to the surgical pneumoperitoneum.
\end{abstract}

Une patiente bien portante de 69 ans est opérée en chirurgie réglée pour une cholécystectomie par laparoscopie. Pendant lintervention, elle présente de l'hypercapnie $\left(\mathrm{PaCO}_{2}=100\right.$ $\mathrm{mmHg}$ ) associée à une acidose respiratoire $(\mathrm{pHa}=7,07)$. Létiologie de cet incident est autibuable à une insufflation percutanée avec absorption de $\mathrm{CO}_{2}$ causée par un pneumopéritoine d'origine chirurgicale.

Laparoscopic surgery is being performed in many surgical facilities and is growing in popularity. Recently the advent of laparoscopic cholecystectomy (LC) has given anaesthetists new challenges and many complications have been described. ${ }^{1-7}$

This report illustrates the diagnosis and management of an unusual case of intraoperative respiratory acidosis occurring during laparoscopic surgery and considers some practical issues related to anaesthesia for laparoscopic surgery.

\section{Case report}

A 69-yr-old wornan was admitted to hospital for LC. Medical history indicated that she had essential hyper-

Key words

CARBON DIOXIDE: absorption, hypercarbia; COMPLICATIONS: hypercapnia, emphysema; SURGERY: laparoscopy.

Address correspondence to: Dr. D.J. Pearce, P.O. Box 367, Goderich, Ontario N7A 4C6.

Accepted for publication 30th November, 1993. tension which was well controlled with enalapril and hydrochlorothiazide. She denied symptoms of cardiac disease. However, previous echocardiography demonstrated mitral valve prolapse without regurgitation. She was a previous smoker who had stopped many years earlier. She had hypothyroidism which was compensated by thyroid hormone replacement. On physical examination no abnormalities were detected except for a midsystolic click heard at the apex, with no evidence of regurgitant murmur. Chest $x$-ray, ECG, CBC, and electrolytes were within normal limits.

The patient received premedication with lorazepam 1 $\mathrm{mg}$ and ranitidine $150 \mathrm{mg}$ po with $125 \mathrm{ml}$ of water two hours before surgery. ${ }^{3}$ Intraoperative monitors included ECG, automatic BP, axillary temperature probe, pulse oximetry, $\mathrm{PeTCO}_{2}$ and volatile gas concentrations were measured by a Nelcor 2000 monitor. Muscle relaxation was monitored with a peripheral nerve stimulator.

Anaesthesia was induced breathing 100\% oxygen, with fentanyl $100 \mathrm{mg}$, followed by thiopentone $250 \mathrm{mg}$ and muscle relaxation was produced with vecuronium $5 \mathrm{mg}$. The trachea was intubated and anaesthesia was maintained with $\mathrm{N}_{2} \mathrm{O} / \mathrm{O}_{2}$ and isoflurane $(0.5-0.75 \%$ inspired concentration). The lungs were ventilated using a Narcomed $2 \mathrm{~A}$ anaesthetic machine with a Bain circuit with a tidal volume of $600 \mathrm{ml}$, at $12 \mathrm{bpm}$ and I:E ratio of 1:2. The patient received one litre of Ringer's lactate solution in the first hour of surgery.

Within a few minutes of induction of anaesthesia she developed sinus bradycardia and a decrease in systolic blood pressure from $140 \mathrm{mmHg}$ to $105 \mathrm{mmHg}$ which lasted about $30 \mathrm{sec}$. The heart rate returned to $60 \mathrm{bpm}$ after atropine $0.3 \mathrm{mg} i \mathrm{w}$ was given. The $\mathrm{SpO}_{2}$ and $\mathrm{PETCO}_{2}$ remained at $99 \%$ and $32 \mathrm{mmHg}$ respectively, and the temperature remained constant at $35^{\circ} \mathrm{C}$. The surgeon inserted the $\mathrm{CO}_{2}$ insufflation needle periumbilically but required three attempts to achieve an unobstructed flow of $\mathrm{CO}_{2}$ into the peritoneal cavity at a rate of 2 to 3 $\mathrm{L} \cdot \mathrm{min}^{-1}$ maintaining a pressure $<13 \mathrm{mmHg}$. The patient was maintained in Fowler's position. 
Fifteen minutes later, the $\mathrm{PETCO}_{2}$ was noted to have increased from $32 \mathrm{mmHg}$ to $45 \mathrm{mmHg}$ and $\mathrm{SpO}_{2}$ was $99 \%$. As the surgery proceeded without difficulty the PETCO ${ }_{2}$ continued to increase considerably but without haemodynamic instability, oxygen desaturation, or pyrexia. Peak inspiratory airway pressures were $<25 \mathrm{mmHg}$ throughout anaesthesia. In response, the ventilator settings were modified to increase tidal volume to $800 \mathrm{ml}\left(16 \mathrm{ml} \cdot \mathrm{kg}^{-1}\right)$, respiratory rate to $20 \mathrm{bpm}$ and $\mathrm{N}_{2} \mathrm{O} / \mathrm{O}_{2}$ to $4 / 2 \mathrm{~L} \cdot \mathrm{min}^{-1}$ from $3 / 1.5 \mathrm{~L} \cdot \min ^{-1}$. Other causes for hypercapnia were sought and ruled out including, ventilator or circuit leaks, malpositioned endotracheal tube, $\mathrm{CO}_{2}$ embolus, pneumothorax, malignant hyperthermia and airway obstruction.

Approximately $50 \mathrm{~min}$ after induction of anaesthesia, the $\mathrm{PETCO}_{2}$ was $60 \mathrm{mmHg}$. Nitrous oxide was discontinued and $\mathrm{O}_{2}$ delivered at $5 \mathrm{~L} \cdot \mathrm{min}^{-1}$. The patient's neck was distended and some periorbital swelling was noted. Palpation revealed crepitus consistent with subcutaneous emphysema. The surgeon was asked to discontinue $\mathrm{CO}_{2}$ insufflation but felt he could not complete the procedure, which was approaching completion, by doing this. A few more minutes were granted to maintain pneumoperitoneum. An immediate chest $x$-ray ruled out the presence of pneumothorax and pneumomediastinum. Appropriate endotracheal tube position was confirmed radiologically and the presence of gas in the chest wall and neck was evident.

The $\mathrm{PeTCO}_{2}$ climbed to a maximum of $85 \mathrm{mmHg}$ in spite of rapid manual hyperventilation with $100 \%$ oxygen. Arterial blood gas analysis revealed $\mathrm{pH} 7.07, \mathrm{PCO}_{2} 100$ $\mathrm{mmHg}, \mathrm{PO}_{2} 311 \mathrm{mmHg}, \mathrm{HCO}_{3} 28 \mathrm{mmol} \cdot \mathrm{L}^{-1}$, and $\mathrm{TCO}_{2}$ $31 \mathrm{mmol} \cdot \mathrm{L}^{-1}$ indicating an acute respiratory acidosis.

The abdominal trocars were withdrawn after removal of the gallbladder, allowing $\mathrm{CO}_{2}$ to escape from the peritoneal cavity which was followed by a dramatic reduction of the $\mathrm{PETCO}_{2}$. Mechanical ventilation was continued postoperatively after the addition of vecuronium $1 \mathrm{mg}$ and midazolam $2 \mathrm{mg}$ with $100 \% \mathrm{O}_{2} 5 \mathrm{~L} \cdot \mathrm{min}^{-1}, \mathrm{RR}$ $12 \mathrm{bpm}$ and $\mathrm{VT} 800 \mathrm{ml}$. Twenty minutes after release of the pneumoperitoneum the $\mathrm{PETCO}_{2}$ was $51 \mathrm{mmHg}$, $\mathrm{SpO}_{2} 99 \%$ and temperature $35^{\circ} \mathrm{C}$. After another $20 \mathrm{~min}$ the patient was awake and coughing. Neuromuscular blockade was reversed with atropine $0.3 \mathrm{mg}$ and edrophonium $25 \mathrm{mg}$. The trachea was extubated after adequate reversal with the patient breathing spontaneously, achieving normocarbia and adequate oxygenation, $\mathrm{PeTCO}_{2} 42 \mathrm{mmHg}$ and $\mathrm{SpO}_{2} 99 \%$. She was discharged to the recovery room becoming more alert, breathing adequately and showing a marked reduction of her subcutaneous emphysema. The patient proceeded to have an uneventful recovery breathing oxygen by mask at 5 $\mathrm{L} \cdot \min ^{-1}$. Repeat arterial blood gas analysis revealed $\mathrm{pH}$
7.35, $\mathrm{PCO}_{2} 46 \mathrm{mmHg}, \mathrm{PO}_{2} 140 \mathrm{mmHg}, \mathrm{HCO}_{3} 26$ $\mathrm{mmol} \cdot \mathrm{L}^{-1}$, and $\mathrm{TCO}_{2} 27 \mathrm{mmol} \cdot \mathrm{L}^{-1}$. She was discharged home the next day with no sequelae.

\section{Discussion}

This case of a healthy woman who underwent elective laparoscopic surgery illustrates a previously unreported complication, extensive subcutaneous $\mathrm{CO}_{2}$ emphysema resulting in hypercarbia and acute respiratory acidosis. The surgery and anaesthetic commenced in a routine manner until significant rise in $\mathrm{PETCO}_{2}$ was noted. After other causes of hypercarbia had been ruled out the cause of the hypercapnia was attributed to subcutaneous $\mathrm{CO}_{2}$ insufflation.

Previous intraoperative anaesthetic complications have been described including hypotension, hypothermia, nausea and vomiting and oxygen desaturation. Hypercarbia ( $\mathrm{PaCO}_{2}$ increasing by up to $10 \mathrm{mmHg}$ ) has been noted during gynaecological laparoscopy where high insufflation pressures are used ( 20 to $40 \mathrm{mmHg}$ ). Due to the lower insufflation pressures during $\mathrm{LC}$ the $\mathrm{PaCO}_{2}$ and $\mathrm{PeTCO}_{2}$ increases are less. ${ }^{4,5}$ It is recognized that ventilatory settings must be adapted to handle the excess burden of $\mathrm{CO}_{2}$ to the body to preserve normal acidbase milieu. ${ }^{6}$

A working differential diagnosis of the hypercarbia was quickly formulated and other causes ruled out by checking the integrity of the anaesthetic circuit, the position and function of the endotracheal tube, confirming adequate air entry into the lungs. Auscultation of the heart for a mill wheel murmur was done to help rule out pulmonary $\mathrm{CO}_{2}$ embolus. Radial artery blood gas sampling confirmed good oxygenation and considerable hypercarbia as indicated by the noninvasive monitors. The ABG also confirmed a respiratory acidosis with a normal bicarbonate level to exclude metabolic causes of acidosis. This and the lack of hyperthermia or haemodynamic instability ruled out malignant hyperthermia.

One can only speculate that in this case the $\mathrm{CO}_{2}$ tracked subcutaneously and was absorbed resulting in acute hypercarbia and respiratory acidosis. One suspects that the difficult insertion of the insufflating needle may have created a tunnel from the peritoneal cavity to the subcutaneous tissues which created a conduit of low resistance allowing $\mathrm{CO}_{2}$ to collect and be absorbed. During the case the surgeon looked for any obvious site for creation of a fistula but was unable to identify any unusual defects from within the peritoneal cavity or externally over the abdominal wall. The trocars and needles were returned to the manufacturer for inspection of material or mechanical flaws, but none were found.

Anaesthetic management involved discontinuation of $\mathrm{N}_{2} \mathrm{O}$ to prevent further distention of the subcutaneous 
space, and $100 \%$ oxygen $\left(100 \mathrm{ml} \cdot \mathrm{kg}^{-1}\right)$, increased tidal volume and respiratory rate were used to achieve hyperventilation. According to Spoerel and Bain this flow will achieve mild hyperventilation. ${ }^{7}$ In retrospect, the fresh gas flow should have been increased further to be more effective. $\mathrm{A} \mathrm{CO}_{2}$ absorber on the circuit might have proved most useful but was not available. Although the insufflation was carried out in the usual fashion with $\mathrm{CO}_{2}$ flow 2-3 L $\cdot \mathrm{min}^{-1}$ on an automatic demand mode using pressures of $<13 \mathrm{mmHg}$, considerable $\mathrm{CO}_{2}$ accumulation occurred making its elimination difficult. However, the amount of $\mathrm{CO}_{2}$ absorbed was insufficient to create conditions for pulmonary $\mathrm{CO}_{2}$ embolus.

Recommendations to be considered in managing dramatic $\mathrm{CO}_{2}$ absorption during laparoscopic surgery might include: (1) routine and repeated examination of the abdominal wall for subcutaneous gas accumulation; (2) discontinuation of $\mathrm{N}_{2} \mathrm{O}$ as it may exacerbate the tracking of subcutaneous gas; (3) use a $\mathrm{CO}_{2}$ absorber; (4) increase of ventilation to eliminate $\mathrm{CO}_{2} ;(5)$ immediate deflation of the pneumoperitoneum and cessation of $\mathrm{CO}_{2}$ insufflation will dramatically improve the situation and is indicated if the patient is unstable; (6) efforts to rule out other causes of hypercarbia such as inadequate ventilation, pulmonary $\mathrm{CO}_{2}$ embolus, malignant hyperthermia, pneumothorax and consider subcutaneous $\mathrm{CO}_{2}$ emphysema.

In conclusion, an unusual case is presented of respiratory acidosis during laparoscopic cholecystectomy, which was most likely caused by $\mathrm{CO}_{2}$ absorption secondary to severe $\mathrm{CO}_{2}$ emphysema. This entity should be considered in the differential diagnosis of hypercarbia during laparoscopic surgery and appropriate measures should be taken to eliminate carbon dioxide accumulation.

\section{Acknowledgements}

The author thanks Dr. John Bradley and Mrs. Ruth Cunningham for their help in the preparation of this manuscript.

\section{References}

1 Rose DK, Cohen MM, Souter DI. Laparoscopic cholecystectomy: the anaesthetist's point of view. Can $J$ Anaesth. 1992; 39: 809-15.

2 Marco AP. Anaesthesia for a patient undergoing laparoscopic cholecystectomy. Anesthesiology 1990; 73: 1268-70.

3 Coombs DW, Hooper D, Colson T. Pre-anesthetic cimetidine alteration of gastric fluid volume and $\mathrm{pH}$. Anesth Analg 1979; 58: 183-8.

4 Shulman $D$, Aronson $H B$. Capnography in the early diagnosis of carbon dioxide embolism during laparoscopy. Can Anaesth Soc J 1984; 31: 455-9.
5 Versichelen L, Serreyn $R$, Rolly $G$, Vanderkerckhove $D$. Physiopathologic changes during anesthesia administration for gynecologic laparoscopy. J Reprod Med 1984; 29: 697-700.

6 Nyarwaya JB, Samii K, Mazoit $J X$, De Wattevill JC. Are pulse oximetric and capnographic monitoring reliable during laparoscopic surgery for cholecystecomy? Anesthesiology 1991; 75: A453.

7 Bain JA, Spoerel WE. Flow requirements for a modified Mapleson D system during controlled ventilation. Can Anaesth Soc J 1973; 20: 629-36. 